\title{
Effect of Ambient Gas on Flammability Limit of Flat Materials in Microgravity
}

\author{
By Kandai TsubOI, ${ }^{1)}$ Keisuke MARUtA, ${ }^{1)}$ Shuhei TAKAHASHI, ${ }^{2)}$ \\ Tadayoshi IHARA $^{2)}$ and Subrata BHATTACHARJEE ${ }^{3)}$ \\ 1) Mechanical and Systems Engineering Division, Graduate School of Engineering, Gifu University, Gifu, Japan \\ 2) Department of Mechanical Engineering, Gifu University, Gifu, Japan \\ 3) Department of Mechanical Engineering, San Diego State University, San Diego, CA, USA
}

(Received July 22nd, 2015)

\begin{abstract}
The flammability map of a thin PMMA sheet with an opposed flow in microgravity environment was investigated with varying the thermal properties of the ambient gas. We also developed a new model to predict the limiting oxygen concentration (LOC) in $1 \mathrm{~g}$, minimum limiting oxygen concentration (MLOC) and critical opposed flow velocity, $V_{c r}$, at which MLOC was observed. We compared the predicted results with the experiment results by changing the gas-phase properties to validate the model. As the balance gas, nitrogen, carbon dioxide, and argon were used. It was found by experiment that LOC, MLOC, and $V_{c r}$ significantly changed for each balance gas. These differences were reasonably predicted by the scale analysis which included the effects of radiation and kinetics on the suppression of the flame spread.
\end{abstract}

Key Words: Flame Spread, Flammability Map, Ambient Gas, Microgravity

\section{Nomenclature}

A : Pre-exponential factor

$a_{a b s} \quad$ : Absorption coefficient of gas

$c_{g} \quad:$ Specific heat of gas

$c_{s} \quad:$ Specific heat of solid

Da : Damkohler number

E : Activation energy

$\Delta h r \quad$ : Combustion heat

$L_{g} \quad$ : Gas-phase diffusion length scale

$L_{s x} \quad$ : Length of the preheated solid phase

$L_{s y} \quad:$ Thickness of the preheated layer

$R \quad$ : Gas constant

$R_{\text {rad }} \quad$ : Radiation loss number

$T_{f} \quad:$ Characteristic (adiabatic) flame temperature

$T_{v} \quad$ : Constant pyrolysis temperature

$T_{\infty} \quad$ : Ambient temperature

$t_{\text {res }} \quad$ : Residence time

$t_{\text {chem }}:$ Characteristic chemical time

$V_{g} \quad$ : Ambient flow velocity

$V_{f} \quad$ : Flame spread rate

$V_{f, \text { th }} \quad$ : Flame spread rate in thermal regime

$V_{r} \quad$ : Velocity relative to the flame, $V_{r}=V_{g}+V_{f}$

$W \quad$ : Width of the fuel in z-direction

$Y_{o} \quad$ : Oxygen mass fraction of the surrounding

$\alpha_{g} \quad$ : Thermal diffusivity of gas, evaluated at $T_{v}$

$\varepsilon \quad:$ Surface emissivity

$\lambda_{g} \quad$ : Gas-phase conductivity evaluated at $T_{v}$

$\eta \quad$ : Non-dimensional spread rate, $\eta=V_{f} / V_{f, t h}$

$\rho_{g} \quad$ : Gas density evaluated at $T v$

$\rho_{s} \quad:$ Solid density

$\sigma \quad:$ Stefan-Boltzmann constant

$\tau \quad:$ Fuel half-thickness $\omega \quad$ : Chemical reaction rate

\section{Introduction}

For space development, recently, human activity in space such as the International Space Station (ISS) has increased. Because fire is very dangerous, knowing the characteristics of the flame in space is very important. One of the most characteristic features of microgravity environment is the absence of buoyant flow that exists as natural convection $(30 \sim 40 \mathrm{~cm} / \mathrm{s})$ in normal gravity.

Until now, many flammability tests such as NASA STD-6001 ${ }^{1)}$ and ISO-4589-2 have been conducted in normal gravity. On the other hand, in the previous researches, ${ }^{2-6)}$ it was found that flame can exist in lower oxygen concentration with lower opposed flow velocity than natural convection. Therefore, there may remain fire hazard in some conditions to use NASA STD-6001 as flammability standard in microgravity environments.

Hence, we developed a simplified model ${ }^{7}$ that can predict the difference between the flammability limit of a thin material in normal gravity and microgravity environment. The schematic of typical flammability map of a solid material with an opposed flow is shown in Fig. 1. The horizontal axis shows the forced opposed flow velocity relative to the flame on the solid material. In this paper, we define limiting oxygen concentration (LOC) and the minimum limiting oxygen concentration (MLOC) as important indexes of the material. The LOC is an index which can be obtained by ground-based flammability test. In order to find the LOC, we set up a solid thin sample vertically, ignite it at the top end and observe the flame spread with varying the ambient oxygen concentration. The LOC is defined as the minimum oxygen concentration in which steady downward spread achieved. The MLOC is an 
index which indicates the measure of flammability of the material in microgravity environments. In order to find the MLOC, we observe the flame spread in parabolic flights with varying the opposed flow velocity and the oxygen concentration. The MLOC is defined as the minimum oxygen concentration among the all experimental conditions in which steady flame spread is achieved. We also defined the critical opposed velocity, $V_{c r}$, at which the MLOC is

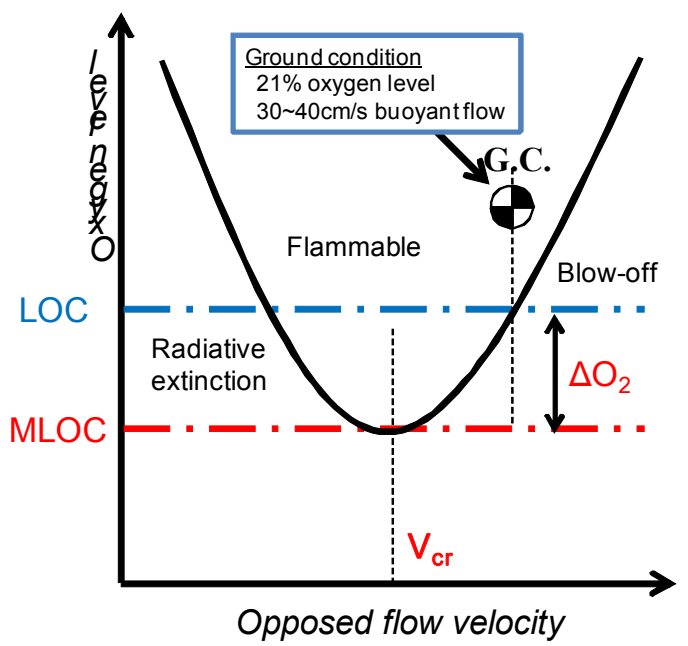

Fig. 1. Flammability map of a solid material with an opposed flow.

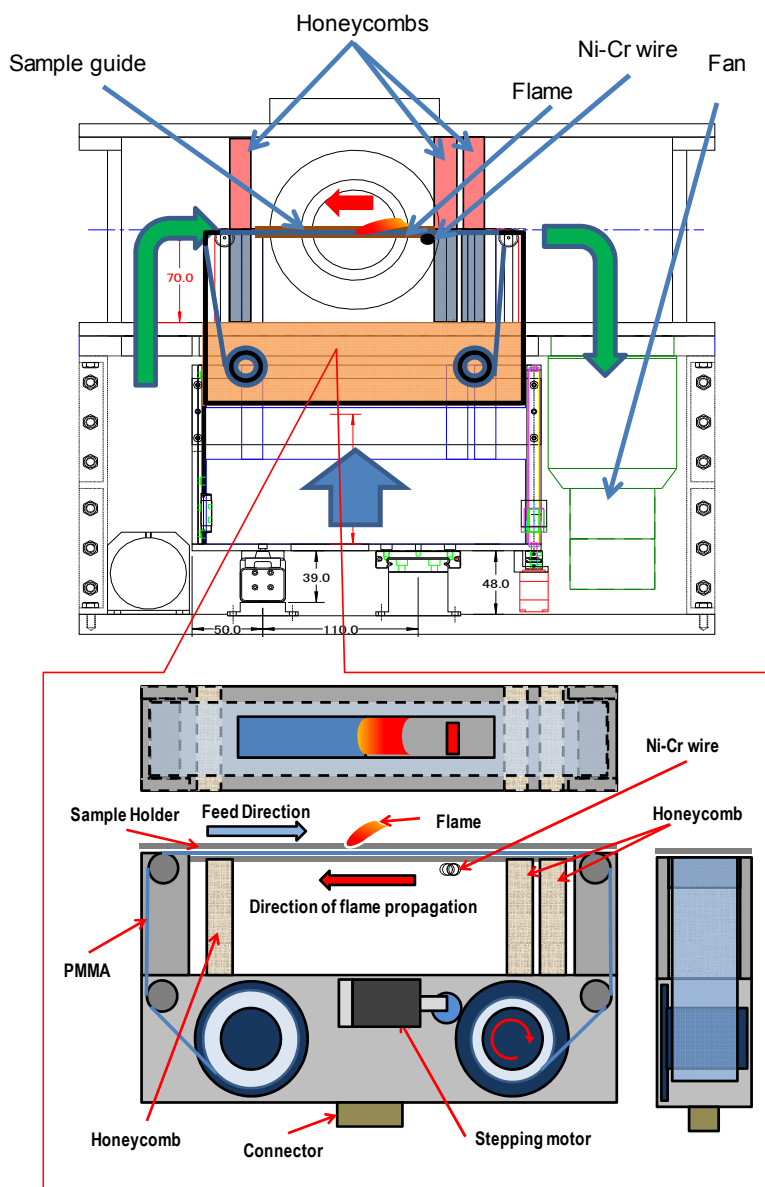

Fig. 2. Schematic of experimental apparatus for parabolic flight. observed. It is easy to find the LOC of a certain material by ground-based tests, but it takes large cost and time to obtain the MLOC of the material. Hence, it is advantageous if the MLOC can be predicted from the LOC and other properties which can be obtained in normal gravity condition. Thus, our final objective is to predict the flammability limit in microgravity environments from ground-based data, such as the LOC or Limiting Oxygen Index (LOI) in ISO 4589-2 using the developed simplified model. Because there are many data of flammability of materials in normal gravity tests, the model will be a useful tool to confirm the flammability of materials in space.

In this article, to validate the developed model, we investigated the flammability of a PMMA film with changing the thermal properties of the ambient gas. Then, we compared the results predicted by the model with the experimental results, and discussed the effect of the difference in the properties of ambient gas.

\section{Experimental Setup}

Figure 2 shows the experimental apparatus. The sample used in this experiment was a thermally thin PMMA sheet (Acryplen: Mitsubishi Rayon Co., Ltd.) with a thickness of $0.125 \mathrm{~mm}$. The PMMA sample, which was $8 \mathrm{~cm}$ in length and $2 \mathrm{~cm}$ in width, was set vertically in a closed chamber of volume $35 \mathrm{~L}$. The sample was ignited at the end of the downstream side with an electrically heated $\mathrm{Ni}-\mathrm{Cr}$ wire, and then the flame propagated upstream. The chamber had a suction fan for creating a flow ranging from 0 to $20 \mathrm{~cm} / \mathrm{s}$ in the test section. The dimensions of the test section were $14 \mathrm{~cm} \times 14 \mathrm{~cm} \times 13 \mathrm{~cm}$, and honeycomb plates were installed on both the upstream side and the downstream side of the test section. Molecular sieves and zeolites were packed inside the test chamber to absorb the water and carbon dioxide generated during the combustion process. For the $\mathrm{CO}_{2}$ balance condition, we replaced the molecular sieves with glass beads. A pressure transducer, a thermocouple, and an oxygen sensor were also installed to monitor the pressure, temperature, and oxygen concentration, respectively.

The flame spread behavior was recorded with a visible CCD camera and an IR camera to obtain the spread rate and the length of the preheat zone on the PMMA sheet, respectively. The spread rate $V_{f}$ was defined as the average spread rate in 5 seconds. The oxygen level and the balance of the ambient gas were varied as parameters. We choose nitrogen $\left(\mathrm{N}_{2}\right)$, argon $(\mathrm{Ar})$ and carbon dioxide $\left(\mathrm{CO}_{2}\right)$ for the balances to change thermal properties of the ambient gas (see Table 1).

In the normal gravity test to obtain the LOC, we set the apparatus vertically so that flame spread downward direction. In order to obtain the MLOC in a microgravity environment, we then conducted 20-s parabolic flight experiments by Diamond Air Service (DAS). The downstream end of the sample was ignited by the Ni-Cr wire $10 \mathrm{~s}$ before the onset of microgravity. When the initial oxygen concentration was lower than the LOC, we could not ignite the sample before the 
Table 1. Properties of balance gases at $300 \mathrm{~K}$ and $1 \mathrm{~atm}$.

\begin{tabular}{|c|c|c|c|c|}
\hline & $\begin{array}{c}C p \\
{[\mathrm{~J} / \mathrm{mol} \mathrm{K}]}\end{array}$ & $\begin{array}{c}\lambda_{g} \\
{[\mathrm{~W} / \mathrm{m} \mathrm{K}]}\end{array}$ & $\begin{array}{c}\alpha_{g} \\
{\left[\mathrm{~mm}^{2} / \mathrm{s}\right]}\end{array}$ & $a_{a b s}$ \\
\hline $\mathrm{N}_{2}$ & 29.06 & 0.0249 & 21.1 & 0.0 \\
\hline $\mathrm{CO}_{2}$ & 37.20 & 0.0164 & 10.9 & 0.6 \\
\hline $\mathrm{Ar}$ & 20.78 & 0.0178 & 21.1 & 0.0 \\
\hline
\end{tabular}

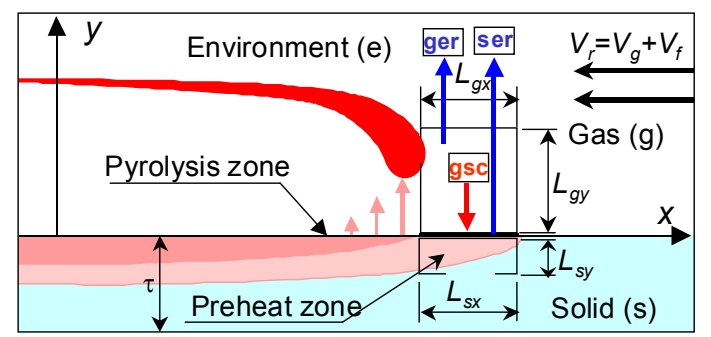

Fig. 3. Schematic of the 2D flame for scale analysis.

onset of microgravity. Hence, under such conditions, we ignited the sample at the onset of microgravity.

\section{Scale Analysis}

In order to discuss the impact of the parameters concerning with the flame spread, scale analysis ${ }^{8,9)}$ was developed for two-dimensional flame spread over a solid material. The schematic of the flame front is shown in Fig. 3.

The heat balance in the preheat zone with low opposed flow is expressed by the following equation.

$V_{f} \rho_{s} c_{s} L_{s y} W\left(T_{v}-T_{\infty}\right)+Q_{r a d}=\lambda_{g} \frac{\left(T_{f}-T_{v}\right)}{L_{g y}} L_{g x} W$

where $Q_{\text {rad }}=\varepsilon\left(1-a_{a b s}\right) \sigma\left(T_{v}^{4}-T_{\infty}^{4}\right) L_{s x} W$.

This equation means that the heat conduction due to the temperature gradient in the preheat zone balances the sum of the heat to preheat the solid material and the heat emitted from the heated surface to the surroundings by radiation.

In the thermal regime, the radiation term is negligible and the spread rate is derived as Eq. (2). ${ }^{10)}$

$V_{f, t h} \sim \frac{\lambda_{g}}{\rho_{s} c_{s} \tau} \frac{T_{f}-T_{v}}{T_{v}-T_{\infty}}$

Introducing the non-dimensional spread rate, $\eta=V_{f} / V_{f, t h}$, which is shown in Fig. 1, Eq. (1) can be reduced to the following non-dimensional equation.

$\eta+R_{\text {rad }}=1$ where $R_{\text {rad }} \sim \frac{\varepsilon\left(1-a_{a b s}\right) \sigma\left(T_{v}^{4}-T_{\infty}^{4}\right)}{\rho_{g} c_{g} V_{r}\left(T_{f}-T_{v}\right)}$

Eq. (3) means that if $R_{\text {rad }}$ approaches unity, $\eta$ approaches zero; thus, radiative extinction occurs. It is found that $R_{\text {rad }}$ becomes larger as the relative opposed-flow $V_{g}$ becomes smaller. Therefore, if the opposed-flow velocity $V_{g}$ is small enough that $R_{\text {rad }}$ is close to 1 , the regime changes to the microgravity regime.

On the other hand, if the opposed-flow velocity $V_{g}$ is much higher, the regime changes to the kinetic regime. The ratio of the residence time to the characteristic chemical time is defined as Damkohler number, expressed in Eq. (4).

$$
\begin{aligned}
& t_{\text {res }} \equiv L_{g} / V_{r}, t_{\text {chem }} \equiv \rho_{g} / \dot{\omega}=\left[\rho_{g} Y_{O} A \exp \left(-E / R T_{f}\right)\right]^{-1} \\
& D a \equiv \frac{t_{\text {res }}}{t_{\text {chem }}} \sim \frac{\alpha_{g}}{V_{r}^{2}} \rho_{g} Y_{O} A \exp \left(-E / R T_{f}\right)
\end{aligned}
$$

The Da also represents the ratio of heat needed to sustain gas-phase reaction to the total heat in the preheat zone.

$$
D a \equiv \frac{t_{\text {res }}}{t_{\text {chem }}} \sim \frac{L_{g} / V_{r}}{\rho_{g} / \dot{\omega}}=\frac{L_{g}{ }^{2} W \dot{\omega} \Delta h_{r}}{\rho_{g} c_{g} L_{g} W V_{r}\left(T_{f}-T_{v}\right)}
$$

Therefore, we assumed that the conduction heat from the flame to the solid is reduced by the factor of $(1-1 / D a)$. Thus, we obtained Eq. (5) to express the effect of $\mathrm{Da}$ on flame spread rate with high opposed flow.

$V_{f} \rho_{s} c_{s} L_{s y} W\left(T_{v}-T_{\infty}\right)=\left(1-\frac{1}{D a}\right) \lambda_{g} \frac{\left(T_{f}-T_{v}\right)}{L_{g y}} L_{g x} W$

Using the two non-dimensional factors $R_{\text {rad }}$ and $\mathrm{Da}$, we could draw the flammability map in Fig. 3 that the vertical line shows oxygen level and the horizontal one opposed flow velocity. However, the effects of both $R_{\text {rad }}$ and Da suppress the flame spread near the flammability limit. Therefore, we combined two non dimensional factors and obtained Eq. (6).

$\eta+R_{\text {rad }}+\frac{1}{D a}=1$

Using this equation, U-shape curve of the flammability limit like as shown in Fig. 1 can be obtained. The model predicts that the limiting oxygen concentration shows its minimum value at a certain opposed flow velocity. We found the minimum oxygen concentration (MLOC) and the critical flow velocity, $V_{c r}$, where MLOC is achieved from the predicted map. Then we compared these values with the experimental results by parabolic flight.

\section{Results and Discussion}

Figure 4 shows the flammability map with $\mathrm{N}_{2}$ balance obtained by the parabolic flight experiments. The solid circle means that the flame survived until the end of the microgravity environment. The cross means that ignition failed or extinction occurred until the end of the microgravity environment. Further, the results of downward spread tests conducted in normal gravity are plotted on the flammability map as open circles assuming that the buoyant flow velocity is $35 \mathrm{~cm} / \mathrm{s}$. The number beside the symbol expresses the flame spread rate calculated by observing the flame spread distance for 5 seconds during microgravity environment.

In $\mathrm{N}_{2}$ balance, we could observe the flame spread below the LOC. The extinction limit oxygen concentration in the normal gravity was $17 \%$, whereas that in the microgravity was $14.7 \%$, which was $2.3 \%$ lower. However, the MLOC predicted by the model was $13 \%$, which was $1.7 \%$ lower than experiment results. Therefore, the simplified model underestimated the flammability limit. The developed model can predict the critical flow velocity, $V_{c r}$, at which the flame spread becomes 
most robust. In nitrogen balance, the $V_{c r}$ was expected near $8 \mathrm{~cm} / \mathrm{s}$ as shown in Fig. 4. Then, we draw curve of the spread rate versus opposed flow at several oxygen levels near MLOC in Fig. 5. In order to plot the spread rate at a certain oxygen concentration, we calculate the spread rate by an interpolation method as follows. If there are spread rate data at $\mathrm{y} 1 \%$ oxygen concentration and y $2 \%$ oxygen concentration, we calculate the flame spread rate at $\mathrm{x} \%$ which is between $\mathrm{y} 1 \%$ and $\mathrm{y} 2 \%(\mathrm{y} 1<\mathrm{x}<\mathrm{y} 2)$ as

$$
V_{f, x}=\frac{(y 2-x) V_{f, y 1}+(x-y 1) V_{f, y 2}}{y 2-y 1} .
$$

In $\mathrm{N}_{2}$ balance, the maximum spread rate was observed at $V_{g}$ of $10 \mathrm{~cm} / \mathrm{s}$, which was close to the predicted value.

In $\mathrm{CO}_{2}$ balance, the LOC was higher than that in $\mathrm{N}_{2}$ balance, because flame temperature became lower than that in $\mathrm{N}_{2}$ balance and Damkohler number decreased. The obtained results are shown in Figs. 6 and 7. This is due to the difference of $\mathrm{C}_{\mathrm{p}}$ (shown in Table 1). Additionally, the MOLC, $V_{c r}$ was different from that in $\mathrm{N}_{2}$ balance because there is significant effect of re-absorption of radiative energy ${ }^{11)}$ in $\mathrm{CO}_{2}$ balance and the radiation limit curve shifted to lower opposed velocity side. From the above reasons, $\Delta \mathrm{O}_{2}$ value was larger than that in $\mathrm{N}_{2}$ balance. We could observe the flame spread below the LOC. The extinction limit oxygen concentration in the normal gravity was $24.3 \%$, whereas that in the microgravity was $19.2 \%$, which was $5.1 \%$ lower. However, the MLOC predicted by the model was $15.4 \%$, which was $3.8 \%$ lower than experiment results. Therefore, the simplified model underestimated the flammability limit. However, the trend of the $\Delta \mathrm{O}_{2}$ value in $\mathrm{CO}_{2}$ balance being much larger than that in $\mathrm{N}_{2}$ balance agreed with the prediction. In $\mathrm{CO}_{2}$ balance, the maximum spread rate was observed at $\mathrm{V}_{\mathrm{g}}$ of $10 \mathrm{~cm} / \mathrm{s}$ at relatively high oxygen level. However, it shifted lower velocity region as it approaches the MLOC. This result agreed with the prediction that the critical $V_{c r}$ of $\mathrm{CO}_{2}$ balance is smaller than other balance gas.

In Ar balance, the LOC was lower than that in $\mathrm{N}_{2}$ balance, because flame temperature became higher than $\mathrm{N}_{2}$ balance and Damkohler number increased. The obtained results are shown in Figs. 8 and 9. This is the same reason as that mentioned earlier in $\mathrm{CO}_{2}$ balance. Therefore $\Delta \mathrm{O}_{2}$ value was smaller than that in $\mathrm{N}_{2}$ balance. We could observe the flame spread below the LOC. The extinction limit oxygen concentration in the normal gravity was $12.9 \%$, whereas that in the microgravity was $11.6 \%$, which was $1.3 \%$ lower. However, the MLOC

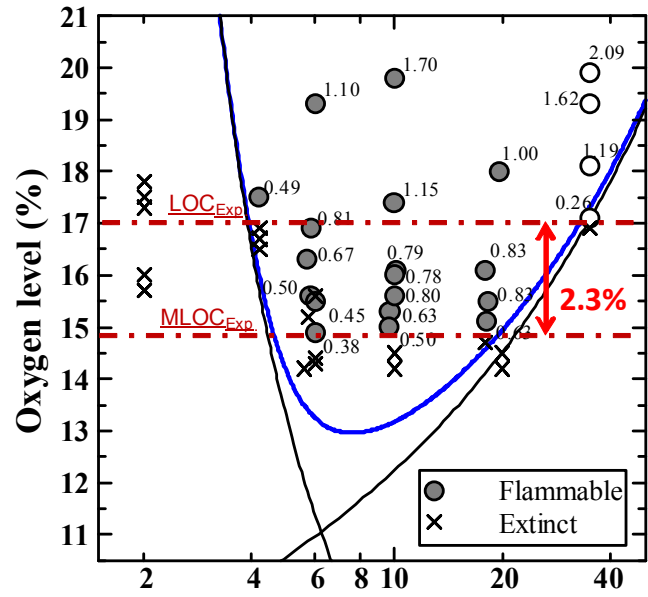

Opposed flow velocity, $\mathrm{Vg}(\mathrm{cm} / \mathrm{sec})$

Fig. 4. Flammability map in $\mathrm{N}_{2}$ diluent.

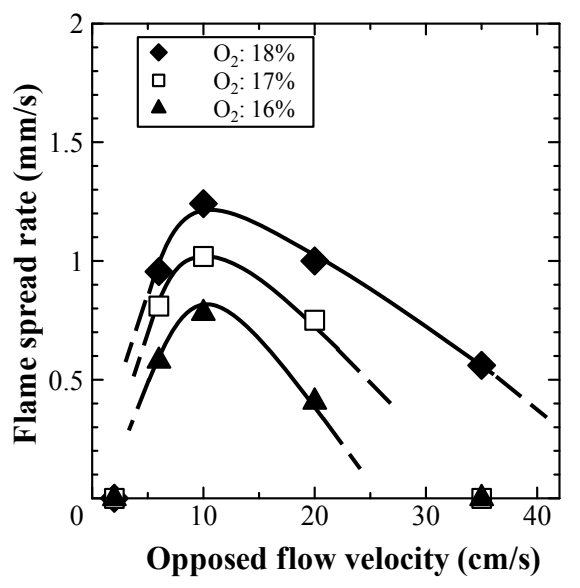

Fig. 5. Flame spread rate vs. opposed flow velocity in $\mathrm{N}_{2}$ diluent.

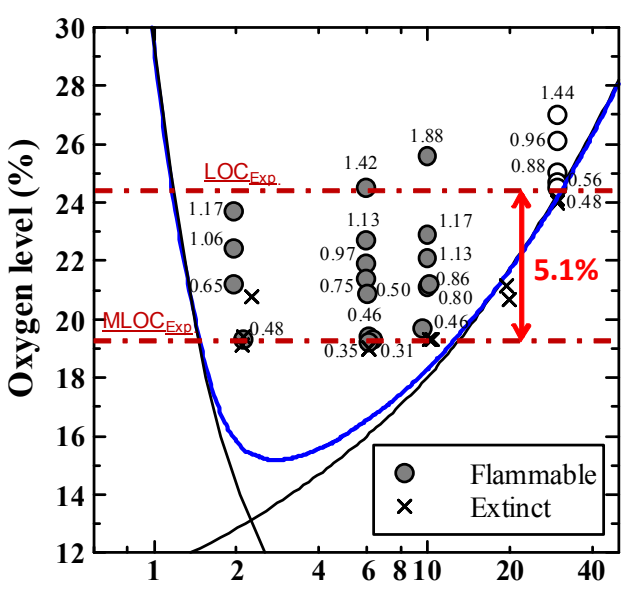

Opposed flow velocity, $\mathrm{Vg}(\mathrm{cm} / \mathrm{sec})$

Fig. 6. Flammability map in $\mathrm{CO}_{2}$ diluent.

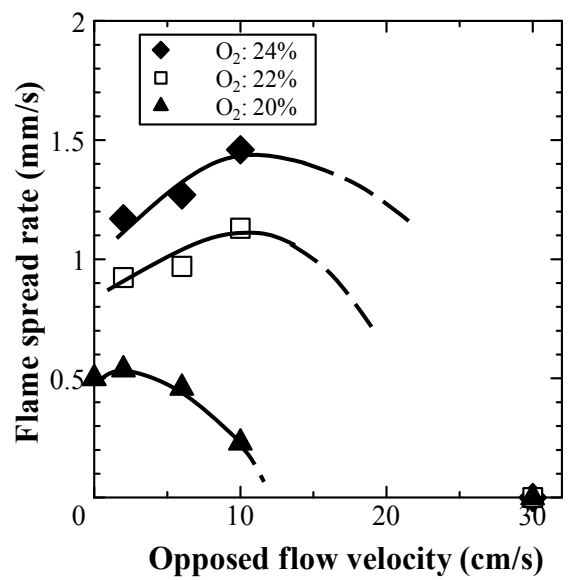

Fig. 7. Flame spread rate vs. opposed flow velocity in $\mathrm{CO}_{2}$ diluent. 
predicted by the model was $9.2 \%$, which was $2.4 \%$ lower than experiment results. Therefore, the simplified model underestimated the flammability limit. However, the trend of the $\Delta \mathrm{O}_{2}$ value in Ar balance being much smaller than that in the $\mathrm{N}_{2}$ balance agreed with the prediction. The observed $V_{c r}$ was near $9 \mathrm{~cm} / \mathrm{s}$, which agreed with the predicted value by the model.

Figure 10 shows the preheat zone taken by IR camera. It was found that the preheat zone length increases with the decrease of opposed flow velocity. This is because the preheat zone length is inversely proportional to the opposed flow velocity $\left(L_{g}=\alpha / V_{g}\right)$. In $\mathrm{CO}_{2}$ balance, the preheat zone length is much smaller than those in $\mathrm{N}_{2}$ balance. This is because the thermal diffusivity of $\mathrm{CO}_{2}$ is smaller than $\mathrm{N}_{2}$. These were consistent with the prediction by scale analysis.

The obtained results are summarized in Table 2. From these results, it was found that the simplified model underestimated the MLOC in all balance gas conditions. It is thought that the

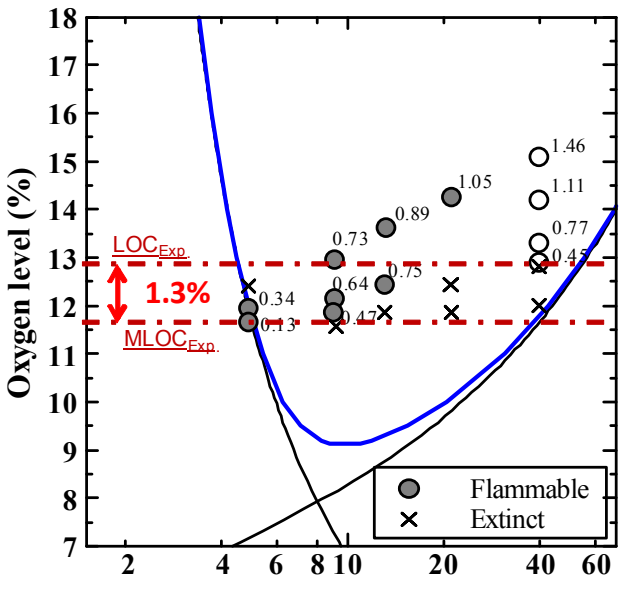

Opposed flow velocity, $\operatorname{Vg}(\mathrm{cm} / \mathrm{sec})$

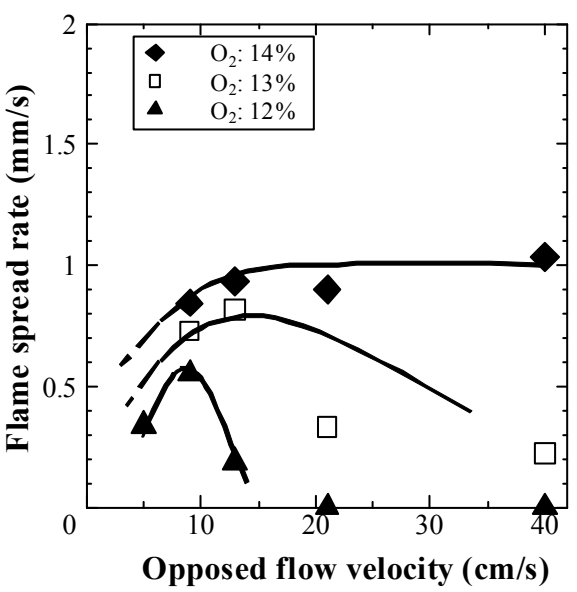

Fig. 9. Flame spread rate vs. opposed flow velocity in Ar diluent.

Fig. 8. Flammability map in Ar diluent.

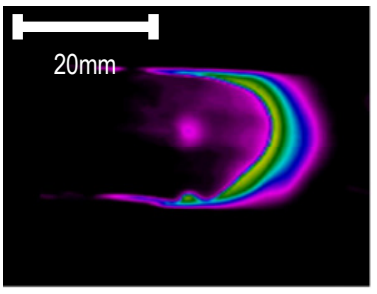

$\mathrm{O}_{2}=17.4 \%, \mathrm{~V}_{\mathrm{g}}=10 \mathrm{~cm} / \mathrm{s}$

(a) $\mathrm{N}_{2}$ balance

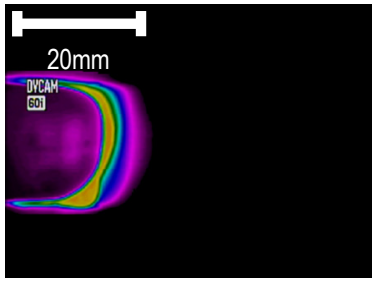

$\mathrm{O}_{2}=21.9 \%, \mathrm{~V}_{\mathrm{g}}=10 \mathrm{~cm} / \mathrm{s}$

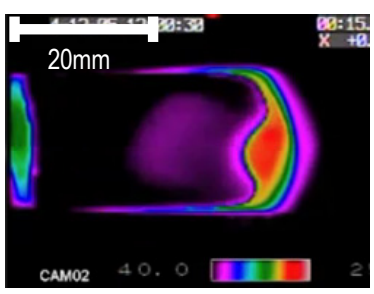

$\mathrm{O}_{2}=14.3 \%, \mathrm{~V}_{\mathrm{g}}=20 \mathrm{~cm} / \mathrm{s}$

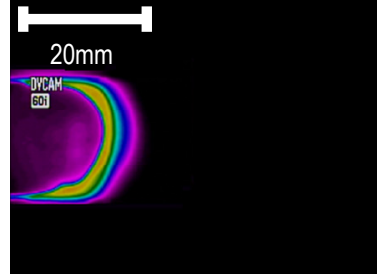

$\mathrm{O}_{2}=21.7 \%, \mathrm{~V}_{\mathrm{g}}=6 \mathrm{~cm} / \mathrm{s}$

(b) $\mathrm{CO}_{2}$ balance

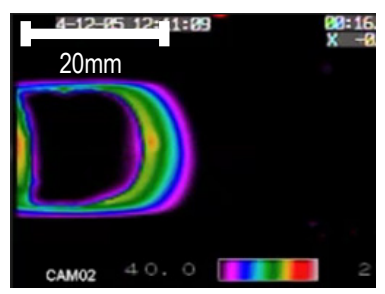

$\mathrm{O}_{2}=13.0 \%, \mathrm{~V}_{\mathrm{g}}=9 \mathrm{~cm} / \mathrm{s}$

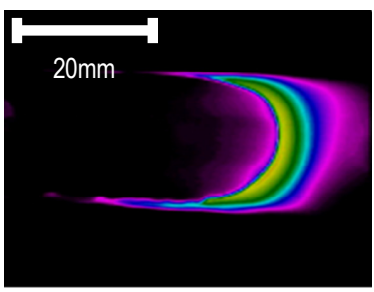

$\mathrm{O}_{2}=16.9 \%, \mathrm{~V}_{\mathrm{g}}=6 \mathrm{~cm} / \mathrm{s}$

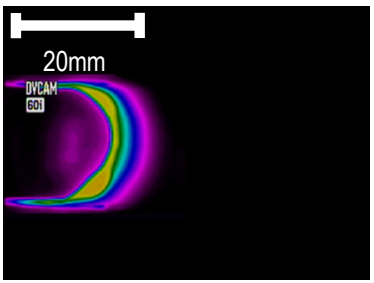

$\mathrm{O}_{2}=21.4 \%, \mathrm{~V}_{\mathrm{g}}=2 \mathrm{~cm} / \mathrm{s}$

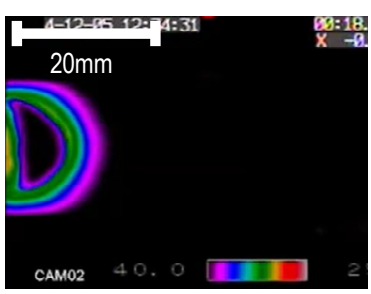

$\mathrm{O}_{2}=11.9 \%, \mathrm{~V}_{\mathrm{g}}=5 \mathrm{~cm} / \mathrm{s}$

(c) Ar balance

Fig. 10. Comparison between the preheat zone length of the sold phase in each balance gas condition. 
reason of the discrepancy is as follows. In the model, we assume that the extinction occurs at $\eta=0$, that is, the breakdown of the heat balance is only the cause of extinction. However, this criteria is very strong, and there are several results $^{5,12)}$ that the extinction occurs at $\eta \sim 0.2-0.5$ not $\eta=0$. Therefore, for more accurate prediction, the model needs some modification for the treatment of $\eta$. However, the model gives safe side predictions and it would be a useful expression to give fire criteria of materials in space.

Table 2. Comparison between LOC and MLOC, and critical opposed flow velocity, $\mathrm{Vcr}$ for each balance gas.

\begin{tabular}{|c|c|c|c|c|}
\hline \multicolumn{2}{|c|}{ Balance gas } & $\mathrm{N}_{2}$ & $\mathrm{CO}_{2}$ & $\mathrm{Ar}$ \\
\hline \multirow{2}{*}{ LOC } & Predicted & $17.0 \%$ & $24.0 \%$ & $12.0 \%$ \\
\cline { 2 - 5 } & Measured & $\mathbf{1 7 . 0} \%$ & $\mathbf{2 4 . 3 \%}$ & $\mathbf{1 2 . 9 \%}$ \\
\hline \multirow{2}{*}{ MLOC } & Predicted & $13.0 \%$ & $15.4 \%$ & $9.2 \%$ \\
\cline { 2 - 5 } & Measured & $\mathbf{1 4 . 7 \%}$ & $\mathbf{1 9 . 2 \%}$ & $\mathbf{1 1 . 6 \%}$ \\
\hline \multirow{2}{*}{$\Delta \mathrm{O}_{2}$} & Predicted & $-4 \%$ & $-8.6 \%$ & $-2.8 \%$ \\
\cline { 2 - 5 } & Measured & $\mathbf{- 2 . 3 \%}$ & $\mathbf{- 5 . 1 \%}$ & $\mathbf{- 1 . 3 \%}$ \\
\hline \multirow{2}{*}{$V_{c r}$} & Predicted & $8 \mathrm{~cm} / \mathrm{s}$ & $3 \mathrm{~cm} / \mathrm{s}$ & $9 \mathrm{~cm} / \mathrm{s}$ \\
\cline { 2 - 5 } & Measured & $\mathbf{1 0} \mathbf{c m} / \mathbf{s}$ & $\mathbf{2 ~ 6 c m} / \mathbf{s}$ & $\mathbf{9 c m} / \mathbf{s}$ \\
\hline
\end{tabular}

\section{Conclusions}

We conducted parabolic flight experiments using three balance gases to investigate the accuracy of the developed model. In all balance gases, it was found that limiting oxygen concentration in microgravity was lower than that in normal gravity. The $\Delta \mathrm{O}_{2}$ in $\mathrm{CO}_{2}$ balance was the largest value. On the other hand, the $\Delta \mathrm{O}_{2}$ in $\mathrm{A}_{\mathrm{r}}$ balance was the smallest value. These were consistent with results expected from the developed model. It was also found that the developed model can predict the critical flow velocity at which the flame spread becomes most intensive. On the other hand, the developed model underestimated the MLOC with using the strong extinction criteria, $\eta=0$, but it is safe side discrepancy and the predicted values can work as the fire safety limits in space.

\section{Acknowledgments}

This study was conducted as part of the SOLID COMBUSTION project and FLARE project supported by JAXA. We are thankful to the staff of DAS for their excellent technical support.

\section{References}

1) NASA-STD-6001 B: Flammability, Offgassing, and Compatibility Requirements and Test Procedures, 2011.

2) Prasad, K., Nakamura, Y., Olson, S. L., Fujita, O., Nishizawa, K., Ito, K., Kashiwagi, T., Proc. Combust. Inst. 29 (2002), pp. 2553-2560.

3) Kashiwagi, T., McGrattan K. B., Olson, S. L., Fujita, O., Kikuchi, M., Ito, K., Proc. Combust. Inst. 26 (1996), pp. 1345-1352.

4) Olson, S. L., Ferkul, P. V., T'ien, J. S., Proc. Combust. Inst. 22 (1989), pp. 1213-1222.

5) Olson, S. L., Miller, F. J., Proc. Combust. Inst. 32 (2009), pp. 2445-2452.

6) Sacksteder, K. R., T'ien, J. S., Proc. Combust. Inst. 25 (1994), pp. 1685-1692.

7) Takahashi, S., Ebisawa, T., Bhattacharjee, S., and Ihara, T., Proc. Combust. Inst. 35 (2015), pp. 2535-2543.

8) Bhattachrjee, S., West, J., Altenkirch, R. A., Proc. Combust. Inst. 26 (1996), pp. 1477-1485.

9) Bhattacharjee, S., Ayala, R., Wakai, K., Takahashi, S., Proc. Combustion Inst. 30 (2005), pp. 2279-2286.

10) de Ris, J. N., Proc. Combust. Inst. 12 (1969), pp. 241-255.

11) Son, Y., Ronney, P. D., Proc. Combust. Inst. 29 (2002), pp. 2587-2594.

12) Bhattacharjee, S., Wakai, K., Takahashi, S., Combust. Flame 132 (2002), pp. 523-532. 